cảm ứng tăng sinh mạch do tế bào u kích thích tạo ra [5]

Theo Zeming Liu và CS, Độ nhạy, độ đặc hiệu, giá trị tiên đoán dương, giá trị tiên đoán âm và độ chính xác tương ứng để dự đoán các hạch di căn đặc điểm mạch máu bất thường là $32,8 \% ; 77,6 \% ; 45,2 \% ; 67,3 \% ; 61,5 \%$

Kết hợp từ 2 đặc điểm siêu âm trở lên để chẩn đoán hạch cổ di căn ở bệnh nhân UTTGTBH đã phẫu thuật cắt giáp và điều trị 131I, siêu âm phát hiện được 74 hạch di căn và 49 hạch không di căn trong tổng số 123 hạch (Bảng 6). Đối chiếu với kết quả mô bệnh học, chúng tôi thấy độ nhạy (Sn), độ đặc hiệu (Sp), giá trị chẩn đoán dương tính (PPV), giá trị chẩn đoán âm tính (NPV), độ chính xác (Acc) của phương pháp siêu âm 2D kết hợp siêu âm Dopper lần lượt là $90.4 \%, 84 \%, 89.2 \%, 85.7 \%$ và $87.8 \%$.

Theo Nguyễn Thanh Thủy và CS, độ nhạy (Sn), độ đặc hiệu (Sp), giá trị chẩn đoán dương tính (PPV), giá trị chẩn đoán âm tính (NPV), độ chính xác (ACc) của phương pháp siêu âm 2D kết hợp siêu âm Dopper lần lượt là 95,08\%, 79,2\%, $92 \%, 86 \%$ và $90,6 \%$. [1]

Đường cong ROC thể hiện mối liên hệ giữa các đặc điểm trên siêu âm với các hạch bạch huyết di căn (Hình 1). Diện tích dưới đường cong là 0,872 , cho thây độ chính xác của phép thử là tốt.

Trong nghiên cứu của Zeming Liu và CS, Đường cong ROC thể hiện mối liên hệ giữa các đặc điểm trên siêu âm với các hạch bạch huyết di căn có diện tích dưới đường cong là 0,793.

\section{KẾT LUẦN}

Nghiên cứu của chúng tôi cho thây rằng các đặc điểm trên siêu âm về hình dạng tròn, hồi âm, vôi hóa, mất rốn hạch và tăng sinh mạch bất thường là những tiêu chuẩn siêu âm hữu ích để phân biệt giữa các hạch cổ di căn và không có di căn trên bệnh nhân ung thư tuyến giáp thể biệt hóa đã phẫu thuật và điều trị ${ }^{131} \mathrm{I}$. Độ nhạy, độ đặc hiệu, giá trị tiên đoán dương, giá trị tiên đoán âm, độ chính xác của phương pháp siêu âm 2D kết hợp với Dopper lần lượt là 90,4\%, $84 \%, 89,2 \%, 85,7 \%$ và $87,8 \%$.

\section{TÀI LIÊU THAM KHẢO}

1. Nguyễn Thanh Thủy (2020), "' Nghiên cứu đặc điểm hình ảnh hạch ác tính trên siêu âm và giá trị của siêu âm trong chẩn đoán hạch ác tính tại bệnh viên Bạch Mai", Tạp chi Điện Quang Việt Nam. 39, tr. $\operatorname{tr} 68-75$.

2. Liu, Z., et al.(2017), Diagnostic accuracy of ultrasonographic features for lymph node metastasis in papillary thyroid microcarcinoma: a single-center retrospective study. World J Surg Oncol, 15(1): p. 32

3. Ying, M., et al., Sonographic appearance and distribution of normal cervical lymph nodes in a Chinese population. J Ultrasound Med, 1996. 15(6): p. 431-6.

4. Ahuja, A.T., et al., Metastatic cervical nodes in papillary carcinoma of the thyroid: ultrasound and histological correlation. Clin Radiol, 1995. 50(4): p. 229-31.

5. Ying, M., et al., Power Doppler sonography of normal cervical lymph nodes. J Ultrasound Med, 2000. 19(8): p. 511-7

\title{
ĐĂC ĐIỂM LÂM SÀNG CỦA BỆNH NHÂN TRÀO NGƯỢC DẠ DÀY THỰC QUẢN
}

\section{TÓM TẮT.}

Mục tiêu: Mô tả đặc điểm lâm sàng của bệnh nhân trào ngược da dày thực quản tại Bệnh viện đa khoa Y học cổ truyển Hà Nội. Đối tượng: Bệnh nhân trào ngược dạ dày thực quản đến khám và điêu trị từ tháng 06/2021 đến tháng 09/2021. Phương pháp: Nghiên cứu mô tả cắt ngang. Kết quả: Trong thời

*Bệnh viện Đa khoa tỉnh Lào Cai

**Bệnh viện đa khoa YHCT Hà Nội

***Trường Đại học Y Hà Nội

Chịu trách nhiệm chính: Nguyễn Thị Thanh Tú

Email: thanhtu@hmu.edu.vn

Ngày nhận bài: 4.8.2021

Ngày phản biện khoa học: 1.10.2021

Ngày duyệt bài: 7.10.2021

\section{Lý Hải Yến*, Vũ Minh Hoàn**, Nguyễn Thị Thanh Tú ***}

gian nghiên cứu, bệnh viện Y hơc cổ truyền Hà Nội đã điều trị cho 60 bệnh nhẩn: Tuổi trung bình của beẹnh nhân nghiên cứu là $51,95 \pm 15,94$. Tỉ lệ nữ cao hớn nam $(66,67 \%)$. Phần lớn bệnh nhân là lao động trí óc $(38,33 \%)$. Thời gian bị bệnh chủ yếu từ 6 đến 12 tháng $(61,67 \%)$. Có 30,0\% bệnh nhân có sử dụng bia rượu, 21,67\% hút thuốc lá, 33,33\% thường xuyên uống cà phê, $55 \%$ sử dụng thuốc giảm đau nonsteroid; $38,33 \%$ bệnh nhân thứa cân và béo phì. Triệu chứng ợ chua, ợ hơi chiếm tî lệ cao nhất $(88,33 \%)$. Tồng điểm GERD $Q$ trung bình của bệnh nhân khi vào viên là $10,42 \pm 1,72$. Kêt luận: Nghiên cứu đã mô tả đặc điểm lâm sàng của bệnh nhân trào ngược dạ dày thực quản và một số yêu tố liên quan đến bênhi trào ngược dạ dày thực quản.

Từ khóa: Trào ngược dạ dây thực quản, đặc điểm lâm sàng 


\section{SUMMARY \\ CLINICAL CHARACTERISTICS OF PATIENTS WITH GASTROESOPHAGEAL REFLUX DISEASE}

Objectives: To describe clinical characteristics of patients with gastroesophageal reflux disease at Hanoi General Hospital of Traditional Medicine. Subjects: Patients have been diagnosed with gastroesophageal reflux disease from June 2021 to September 2021. Methods: A cross-sectional study. Results: 60 patients were selected for the study: The mean age in the study was $51.95 \pm 15.94$. The rate of female was higher than that of male $(66.67 \%)$. The majority of patients were mental workers $(38.33 \%)$. The disease duration was mainly from 6 to 12 months $(61.67 \%)$. $30.0 \%$ of patients used alcohol; $21,67 \%$ of patients used tobacco; $33,33 \%$ of patients regularly drank coffee; $55 \%$ of patients used nonsteroid analgesics; $38,33 \%$ of patients were overweight and had obese. Symptoms of heartburn, belching accounted for the highest rate $(88.33 \%)$. The mean total GERD Q score of patients on admission was $10.42 \pm 1.72$. Conclusions: This study has described the clinical characteristics of patients with gastroesophageal reflux disease and some factors related to gastroesophageal reflux disease.

Keywords: gastroesophageal reflux disease, clinical characteristics

\section{I. ĐĂT VẤN ĐỀ}

Bệnh trào ngược dạ dày thực quản (GERD Gastroesophageal reflux disease) là một trong những bệnh phổ biễn nhất trong các bệnh đường tiêu hóa trên toàn thế giới. Tî lệ bệnh phổ biến toàn cầu ước tính là $8 \%$ đến $33 \%$, bệnh chiếm từ $18,1 \%$ đến $27,8 \%$ ở Bắc Mỹ, $8,8 \%$ đến $25,9 \%$ ở Châu Âu, $11,5 \%$ đến $35 \%$ ở Đông Nam Á [2]. Tỷ lệ mắc GERD ngày càng gia tăng dẫn đến gánh nặng kinh tế đáng kể về chi phí trực tiếp, gián tiểp và ảnh hưởng xấu đến chất lượng cuộc sống của người bệnh [8]. Tại bệnh viện Y học cổ truyền Hà Nội, GERD là một trong những mặt bệnh thường gặp và có xu hướng gia tăng hàng năm. Để hiểu thêm về đặc điểm lâm sàng của người bệnh và các yếu tố liên quan đến bệnh nhằm phục vụ tốt cho quá trình điều trị, chúng tôi tiên hành nghiên cứu này với mục tiêu: Mô tả đặc điểm lâm sàng của bệnh nhân trào ngược dạ dày thực quản.

\section{II. ĐỐI TƯợNG VÀ PHƯƠNG PHÁP NGHIÊN CỨU \\ 2.1. Đối tượng nghiên cứu}

+ Tiêu chuân lứa chọn: Bệnh nhân có ít nhất 1 trong 2 triệu chứng: nóng rát sau xương ức và/hoặc ợ trớ xuất hiện 2 lần trở lên trong 1 tuần trước đó; Được đánh giá bằng bộ câu hỏi GERD-Q và có điểm GERD-Q từ 8 điểm trở lên; Được nội soi loại trừ các tổn thương ác tính của thực quản- dạ dày, loét da dày tá tràng; Tự nguyện tham gia nghiên cứu, không phân biệt giới tính; Tuổi $\geq 18$ tuổi.

+ Tiêu chuẩn loại trừ: Bệnh nhân bị GERD có kèm theo 1 bệnh lý khác của thực quản (hẹp thực quản, u thực quản, thực quản Barrett...), Đã dùng PPI trong 2 tuần gần nhất, Phụ nữ có thai, cho con bú.

\subsection{Phương pháp nghiên cứu}

2.2.1. Thiết kế nghiên cứu: Nghiên cứu mô tả cắt ngang.

2.2.2. Cỡ mẫu nghiên cứu: 60 bệnh nhân

2.2.3. Chỉ tiêu nghiên cứu

+ Chỉ tiêu về đặc điểm chung: tuổi, giới, nghề nghiệp, thời gian mắc bệnh, BMI, các yêu tổ nguy cớ.

+ Chỉ tiêu về đặc điểm lâm sàng: các triệu chứng lâm sàng: ợ nóng; ợ chua, ợ hơi; đau thượng vị; buồn nôn, nôn; khó ngủ do nóng rát; đau ngực không do tim; ho dai dẳng; ngực sườn đầy tức; phiền muộn khó chịu; ách nghịch (nấc); nuốt chua và tổng điểm GERD Q.

2.3. Thời gian và địa điểm nghiên cứu: Nghiên cứu được tiến hành từ tháng 06/2021 đển tháng 09/2021 tại Bệnh viện Y học cổ truyền Hà Nội.

2.4. Thu nhập và xử lý số liệu: Số liêu được xử lý bằng phần mềm SPSS 20.0 với các thuật toán, tính các tî lệ, giá trị trung bình, độ lệch chuẩn SD.

\section{KẾT QUẢ NGHIÊN CỨU}

\section{1. Đặc điểm chung của bệnh nhân}

Bảng 3.1: Phân bố bệnh nhân theo tuổi và giới

\begin{tabular}{|c|c|c|}
\hline Độ tuối & $\mathbf{n ~ ( 6 0 )}$ & $\mathbf{\%}$ \\
\hline $18-29$ & 5 & 8,34 \\
\hline $30-39$ & 12 & 20,00 \\
\hline $40-49$ & 9 & 15,00 \\
\hline $50-59$ & 14 & 23,33 \\
\hline$\geq 60$ & 20 & 33,33 \\
\hline Tuối trung bình & \multicolumn{2}{|c|}{$51,95 \pm 15,94$} \\
\hline Giới tính & $\mathbf{n ( 6 0 )}$ & $\mathbf{\%}$ \\
\hline Nam & 20 & 33,33 \\
\hline Nữ & 40 & 66,67 \\
\hline
\end{tabular}

Nhóm tuối từ 60 tuối trở lên chiếm tỉ lệ cao nhất (33,33\%). Độ tuổi trung bình là 51,95 \pm 15,94, nhỏ nhất là 21 tuổi, lớn nhất 83 tuối. Tỉ lệ bệnh nhân nữ/nam là 2/1 (nữ: 66,67\%; nam: 33,33\%).

Bảng 3.2. Phân bố bệh nhân theo nghề nghiệp, thời gian mắc bệnh, BMI

\begin{tabular}{|c|c|c|}
\hline Nghề nghiệp & $\mathbf{n}(\mathbf{6 0})$ & $\mathbf{\%}$ \\
\hline Lao động trí óc & 23 & 38,33 \\
\hline
\end{tabular}




\begin{tabular}{|c|c|c|}
\hline Lao động tay chân & 15 & 25,00 \\
\hline Hưu trí & 22 & 36,67 \\
\hline Thời gian mắc bệnh & $\mathbf{n ~ ( 6 0 )}$ & $\mathbf{0}$ \\
\hline$<6$ tháng & 13 & 21,67 \\
\hline $6-12$ tháng & 37 & 61,67 \\
\hline$>12$ tháng & 10 & 16,66 \\
\hline BMI & $\mathbf{n ~ ( 6 0 )}$ & $\mathbf{0}$ \\
\hline Thiếu cân $(<18,5)$ & 7 & 11,67 \\
\hline Bình thường $(18,5-22,9)$ & 30 & 50,00 \\
\hline Thửa cân $(23-24,9)$ & 10 & 16,66 \\
\hline Béo phì $(\geq 25)$ & 13 & 21,67 \\
\hline Chủ yếu bênh xuất hiện ợ nốm
\end{tabular}

Chủ yếu bệnh xuất hiện ở nhóm lao động trí óc (38,33\%). Đa số bệnh nhân thời gian mắc bệnh từ 6 đến 12 tháng $(61,67 \%)$. Bệnh nhân có chỉ số BMI trong giới hạn bình thường chiếm tỉ lệ cao nhất $(50,0 \%)$. Bệnh nhân thừa cân và béo phì chiếm tỉ lệ lần lượt là $16,66 \%$ và $21,67 \%$.

Bảng 3.3. Các yêu tố nguy cớ của đôí tượng nghiên cứu

\begin{tabular}{|c|c|c|c|}
\hline Các yếu tố nguy cơ & Giới & $\mathbf{n ( 6 0 )}$ & $\mathbf{\%}$ \\
\hline Thường xuyên sứ dụng & Nam & 18 & 30,00 \\
\cline { 2 - 4 } rượu, bia & Nữ & 0 & 0 \\
\hline Thường xuyên hút & Nam & 13 & 21,67 \\
\cline { 2 - 4 } thuốc lá & Nữ & 0 & 0 \\
\hline Thường xuyên uống & Nam & 8 & 13,33 \\
\cline { 2 - 4 } cà phê & Nữ & 12 & 20,00 \\
\hline Tiền sứ dùng thuốc & Nam & 10 & 16,67 \\
\cline { 2 - 4 } giảm đau non - steroid & Nữ & 23 & 38,33 \\
\hline
\end{tabular}

Các yếu tố nguy cơ uống bia rượu, sử dụng thuốc lá và cà phê chủ yếu ở gặp nam giới. Có tới $18 / 20$ nam giới $(30,0 \%)$ có sử dụng uống rượu bia, $13 / 20$ nam giới $(21,67 \%)$ hút thuốc lá. Tỉ lệ BN có sử dụng cà phê, thuốc non - steroid gặp ở nữ nhiêuu hơn, với tỉ lệ tương ứng là 20,0\% và $38,33 \%$.

3.2. Đặc điểm lâm sàng

Bảng 3.4. Đặc điểm lâm sàng

\begin{tabular}{|c|c|c|}
\hline Đặc điếm & $\mathbf{n}$ (60) & $\mathbf{0}$ \\
\hline Ợ nóng & 43 & 71,67 \\
\hline Ợ chua, ợ hơi & 53 & 88,33 \\
\hline Đau thượng vị & 24 & 40,00 \\
\hline Buồn nôn, nôn & 6 & 10,00 \\
\hline Khó ngủ do nóng rát & 21 & 35,00 \\
\hline Đau ngực không do tim & 14 & 23,33 \\
\hline Ho dai dằng & 22 & 36,67 \\
\hline Ngực sườn đây tức & 33 & 55,00 \\
\hline Phiền muộn khó chịu & 41 & 68,33 \\
\hline Ách nghịch (nấc) & 12 & 20,00 \\
\hline Nuốt chua & 50 & 83,33 \\
\hline Điếm GERD Q & $10,42 \pm 1,72$ \\
\hline Triêu
\end{tabular}

Triệu chứng ợ chua, ợ hơi chiếm tỉ lệ cao nhất $(88,33 \%)$. Các triệu chứng nuốt chua và ớ nóng cũng chiếm tỉ lệ cao, lân lượt là $83,33 \%$ và 71,67\%. Tổng điểm GERD Q trung bình của bệnh nhân khi vào viện là 10,42 $\pm 1,72$.

\section{BÀN LUÂ̂N}

Nhóm tuổi từ 60 tuổi trở lên chiếm tỉ lệ cao nhất (33,33\%). Độ tuổi trung bình là 51,95 \pm 15,94 . Kết quả này tương đồng với kết quả của Ruigomez nghiên cứu trên 7159 bệnh nhân có bệnh GERD thấy tuổi trung bình là 50,72 $\pm 11,15$ [7]. Tỉ lệ bệnh nhân nữ/nam là 2/1 (nữ: 66,67\%; nam: 33,33\%). Theo Li W và cộng sự (2008) nghiên cứu trên 1405 bệnh nhân, tỉ lệ nam là $63,4 \%$ và nữ là $36,6 \%$ [3]. Sự khác biệt này có lẽ do cõ mẫu của chúng tôi chưa đủ lớn và tỉ lệ bệnh nhân nữ dùng thuốc giảm đau non steroid khá cao (38,33\%).

Đa số bệnh nhân thuộc nhóm lao động trí óc $(38,33 \%)$. Điêu này có thể giải thích do hàng năm bệnh viện đa khoa $Y$ học cổ truyên Hà Nội tiếp nhận một số lượng lớn bảo hiểm y tế của các đối tượng cán bộ khối hành chính sự nghiệp của các cơ quan lân cận. Do đó đối tượng trong nghiên cứu của chúng tôi phân lớn thuộc về nhóm này. Đa số bệnh nhân thời gian mắc bệnh từ 6 đến 12 tháng $(61,67 \%)$. Điêu này phù hợp với nghiên cứu của Nguyễn Cảnh Huy (2015) thời gian mắc bệnh từ 6 đến 12 tháng chiếm $57,9 \%$. Theo Pace $F$ và cộng sự, đa số bệnh nhân có triệu chứng lâm sàng dưới 3 năm. Mức độ nặng của các triệu chứng càng kéo dài liên quan đến tăng mức độ tổn thương viêm thực quản [6]. Tuy nhiên, trong nghiên cứu của chúng tôi, sự liên quan giữa thời gian mắc bệnh và mức độ tổn thương thực quản chưa thực sự rõ ràng có thể do cỡ mẫu còn hạn chế. Bệnh nhân thừa cân và béo phì chiếm tỉ lệ lần lượt là $16,67 \%$ và $21,67 \%$. Béo phì làm giảm áp lực cơ thắt thực quản dưới, gia tăng áp lực ổ bụng từ đó khiến các cơ dạ dày cần nhiêuu thời gian làm việc hơn để tống thức ăn xuống [5].

Kết quả nghiên cứu cũng cho thây có 30,0\% bệnh nhân có sử dụng bia rượu, $21,67 \%$ có thuốc lá, 33,33\% thường xuyên uống cà phê, $55 \%$ sử dụng thuốc giảm đau non- steroid. Hút thuốc lá được coi là một yếu tố căn nguyên của GERD, trong khi uống rượu được coi là một yếu tố thuận lợi kích hoạt các đợt trào ngược chứ không phải là một yếu tố nguyên nhân. Tuy nhiên, cả hút thuốc lá và uống rượu đều có thể làm giảm áp lực cơ thắt thực quản dưới, tạo điêu kiện cho trào ngược. Ngoài ra, việc hút thuốc lá thường xuyên còn làm giảm sản xuất một lượng nước bọt giàu bicarbonate có vai trò quan trọng trong việc đào thải axit thực quản. Rượu cũng có tác động có hại trực tiếp đến niêm mạc thực 
quản, làm tổn thương do axit. Vì vậy, việc cai thuốc lá và hạn chế sử dụng rượu, bia được khuyến khích để làm giảm nguy cơ mắc các triệu chứng của GERD [4].

Triệu chứng ợ chua, ợ hơi chiếm tỉ lệ cao nhất $(88,33 \%)$ và tổng điểm GERD $\mathrm{Q}$ trung bình của bênh nhân là $10,42 \pm 1,72$ điểm. Kết quả nghiên cứu của chúng tôi cũng phù hợp với nghiên cứu của Đoàn Thị Hoài (2006) khi nghiên cứu trên 71 bênh nhân tại Bênh viên Bach Mai và Bệnh viện Đại học $Y$ Hà Nội, tỷ lệ bệnh nhân ợ chua chiếm tỉ lệ $87,7 \%$ và tổng điểm GERD Q trung bình 10,5 $\pm 3,1$ điểm [1].

\section{KẾT LUÂN}

1. Tuổi trung bình trong nghiên cứu là 51,95 $\pm 15,94$ tuổi. Tỉ lệ nữ cao hơn nam (Nữ: $66,67 \%$, Nam: 33,33\%). Phần lớn bệnh nhân là lao động trí óc $(38,33 \%)$. Thời gian bị bệnh chủ yếu từ 6 đến 12 tháng $(61,67 \%)$. Có $30,0 \%$ bệnh nhân có sử dụng bia rượu, $21,67 \%$ có thuốc lá, 33,33\% thường xuyên uống cà phê, $55 \%$ sử dụng thuốc giảm đau nonsteroid; $38,33 \%$ bệnh nhân thừa cân và béo phì.

2. Triệu chứng ợ chua, ợ hơi chiếm tỉ lệ cao nhất $(88,33 \%)$. Các triệu chứng nuốt chua và ợ nóng cũng chiếm tỉ lệ cao (83,33\% và $71,67 \%)$. Tổng điểm GERD $Q$ trung bình của bệnh nhân khi vào viện là $10,42 \pm 1,72$.

\section{TÀI LIÊU THAM KHẢO}

1. Đoàn Thị Hoài (2006), Nghiên cứu đặc điểm lâm sàng, hình ảnh nội soi - mô bênh học và đo $\mathrm{pH}$ thực quản liên tục 24h trong GËRD, Luận văn Thạc sĩ y học, Trường đại học Y Hà Nôi.

2. El-Serag H.B., Sweet S., Winchester C.C. và cộng sự. (2014). Update on the epidemiology of gastro-oesophageal reflux disease: a systematic review. Gut, 63(6), 871-880.

3. Li W., Zhang S.-T., và Yu Z.-L. (2008). Clinica and endoscopic features of Chinese reflux esophagitis patients. World J Gastroenterol WJG, 14(12), 1866-1871.

4. Ness-Jensen E. và Lagergren J. (2017). Tobacco smoking, alcohol consumption and gastrooesophageal reflux disease. Best Pract Res Clin Gastroenterol, 31(5), 501-508.

5. Nocon M., Labenz J., Jaspersen D. và công sứ. (2007). Association of body mass index with heartburn, regurgitation and esophagitis: results of the Progression of Gastroesophageal Reflux Disease study. J Gastroenterol Hepatol, 22(11), 1728-1731.

6. Pace F., Bollani S., Molteni P. và cộng sự (2004). Natural history of gastro-oesophageal reflux disease without oesophagitis (NERD)--a reappraisal 10 years on. Dig Liver Dis Off J Ital Soc Gastroenterol Ital Assoc Study Liver, 36(2), 111-115.

7. Ruigómez A., Wallander M.-A., Johansson S. và cộng sự. (2009). Irritable bowel syndrome and gastroesophageal reflux disease in primary care: is there a link. Dig Dis Sci, 54(5), 1079-1086.

8. Sandhu D.S. và Fass R. (2018). Current Trends in the Management of Gastroesophageal Reflux Disease. Gut Liver, 12(1), 7-16.

\title{
NHÂN MỘT TRƯờNG HỢP UNG THƯ DẠ DÀY SỚM: CHẨN ĐOÁN VÀ ĐIỀU TRI
}

\author{
Vũ Văn Khiên' ${ }^{1}$ Nguyễn Quang Duật ${ }^{2}$,Trần Thị Huyền Trang ${ }^{1}$, \\ Nguyễn Thị Phương Liên ${ }^{1}$, Nguyễn Văn Mạnh ${ }^{1}$, Phạm Hồng Khánh ${ }^{2}$,
}

\section{TÓM TẮT}

Đặt vấn đề: Ung thư dạ dày đứng hàng thứ 5 trong các bệnh ung thư trên thế giới và đứng hàng thứ tư trong các bệnh ung thư tại Việt Nam. Tuy nhiên, phần lớn bệnh nhân khi đến viện đều ở giai đoan muôn. Do vấy, phát hiện sớm và điều tri sớm đóng vai trò quan trọng, liên quan chặt chẽ đến thời gian sống của bệnh nhân. Chúng tôi trình bày về đăc điểm lâm sàng, nội soi, mô bệnh học và phương thức điều trị cho 01 bệnh nhân UTDD sớm. Ca lâm sàng: Bệnh nhân nữ, 56 tuổi. Từ 08/2020, bệnh nhân có

\section{${ }^{1}$ Bệnh viện TWQD 108}

Bềnh viến 103 - Hoc viện Quân y

Chịu trách nhiệm chính: Vũ Văn Khiên

Email: vuvankhien108@yahoo.com.vn

Ngày nhận bài: 13.8.2021

Ngày phản biên khoa hoc: 4.10.2021

Ngày duyệt bài: 15.10 .2021 triệu chứng: Đau thượng vi, khó tiêu, không gầy sút cân. Từ 09/2020-09/2021, bệnh nhân đã được nội soi da dày (06 lần) và sinh thiết 06 lần. Kết quả nổi soi: loét góc bờ cong nhỏ, kích thước $1 \mathrm{~cm}$, bề mặt không nhẵn. Kết quả mô bênh họ: có $1 / 6$ lần sinh thiết, chúng tôi tìm thấy tế bào ung thư (lân sinh thiết cuối cùng: 09/2021). Có 3/6 lần (50\%) có loạn sản tế bào. Bệnh nhân đã được phấu thuật qua nội soi. Kết quả sau mổ: Ung thư biểu mô tuyển, biệt hóa cao, tại góc bờ cong nhỏ dạ dày, pT1aMONO. Sau mổ, bệnh nhân ổn định, không có biến chứng và ra viện. Kết luận: Nội soi và sinh thiết đóng vai trò quan trọng trong phát hiện hiện sớm ung thư dạ dày.

Tư khóa: Ung thư dạ dày, cắt hạ niêm mạc qua nội soi, mô bệnh học

\section{SUMMARY \\ CASE OF EARLY GASTRIC CANCER: DIAGNOSIS AND TREATMENT}

